\title{
Studies on Ultrasonic and Spectroscopic Properties of Binary Liquid Mixture of Ethyl Oleate with Aniline at Different Temperatures
}

\author{
M. SRILATHA ${ }^{1}$, D. CHINNARAO ${ }^{1}$, G. V. GAURAV ${ }^{2}$ and CH. V. PADMARAO ${ }^{* 1}$ \\ ${ }^{1}$ Department of Engineering Chemistry, A.U. College of Engineering (A), \\ Visakhapatnam, India \\ ${ }^{2}$ Dept. of Engineering Chemistry, GVP College of Engineering (A), Visakhapatnam, India \\ padmaraochekuri@gmail.com
}

Received 26 September 2015 / Accepted 28 October 2015

\begin{abstract}
Ultrasonic velocity, viscosity and density of ethyl oleate with aniline have been determined at various temperatures in the range of $303.15 \mathrm{~K}$ to $318.15 \mathrm{~K}$. The ultrasonic velocity, viscosity and density data are used to estimate adiabatic compressibility, intermolecular free length and acoustic impedance along with excess values of adiabatic compressibility, intermolecular free length, acoustic impedance and molar volume. The infrared spectrum of the system, ethyl oleate with aniline has also been recorded at room temperature $(298.15 \mathrm{~K})$. The observed variations of these parameters, with concentration and temperature, are discussed in terms of the intermolecular interactions between the unlike molecules of the binary mixtures.
\end{abstract}

Keywords: Ethyl oleate, Aniline, Ultrasonic speed, Viscosity, Density

\section{Introduction}

Lagemann and Dunbar ${ }^{1}$ were the first to point out the sound velocity method for qualitative determination of the degree of association in liquids. Intermolecular interactions play a vital role in liquid mixtures. They effect the arrangement, coordination and conformations of the molecules in solutions. Recent improvements have found the ultrasonic energy is very useful in medicine, engineering, agriculture and industry ${ }^{2,3}$. Thermodynamic data is essential for many industrial applications such as in the oil and gas industries for flow assurance and oil recovery, in chemical industries for the design and separation processes, in pharmaceutical and polymer industries for solvent selection and emission control and recently in biotechnology for aggregation of proteins and several protein separations. Volumetric and acoustic properties of binary liquid mixtures containing polar and self-associated components exhibit significant deviations from ideality due to difference in size of molecules and possible hydrogen bonding interaction between unlike molecules. In extension to our previous work here we report the results of our studies on ultrasonic and spectroscopic properties of binary mixture of ethyl oleate with Aniline. From the experimental values of ultrasonic velocity viscosity and density, adiabatic compressibility, 
intermolecular free length, acoustic impedance and also their excess values with excess molar volume have been evaluated. Further, the infrared spectra of ethyl oleate with aniline have also been recorded at room temperature (298.15 K).

\section{Experimental}

All the materials procured of Sigma-Aldrich AR grade and glassware used of Borosilicate make. Organic liquid ethyl oleate $\left(\mathrm{C}_{20} \mathrm{H}_{38} \mathrm{O}_{2}, 310.51 \mathrm{~g} / \mathrm{mol}\right)$, aniline of AR grade were procured from Sigma-Aldrich are used directly without purification. The densities and viscosities of the liquid compounds were measured (Table 1) with specific gravity bottle and Ostwald viscometer pre calibrated with $3 \mathrm{D}^{4}$ water of Millipore to nearest $\mathrm{mg} / \mathrm{mL}$. The time taken for flow of viscous fluid in Ostwald viscosity meter is measured to a nearest $0.01 \mathrm{sec}$. Borosilicate glassware, Japan make Shimadzu electronic balance of sensitivity $+0.001 \mathrm{~g}$ and constant temperature water bath of accuracy $\pm 0.1 \mathrm{~K}$ were used while conducting the experiments. $2 \mathrm{MHz}$ ultrasonic interferometer model no. F-05 with least count of micrometer $0.001 \mathrm{~mm}$ of Mittal Enterprises ${ }^{5}$ was used for calculating velocities of sound waves and all the tests were conducted as per ASTM standard ${ }^{6}$ procedures (Table 1). FTIR spectra were obtained with a Bruker ALPHA FT-IR spectrometer.

Table 1. Experimental and literature values of density $(\rho)$, viscosity $(\eta)$ and velocity (U) of $2 \mathrm{MHz}$ ultrasonic wave for pure aniline

\begin{tabular}{|c|c|c|c|c|c|c|c|c|}
\hline \multirow{2}{*}{ Parameter } & \multicolumn{2}{|c|}{$303.15 \mathrm{~K}$} & \multicolumn{2}{|c|}{$308.15 \mathrm{~K}$} & \multicolumn{2}{|c|}{$313.15 \mathrm{~K}$} & \multicolumn{2}{|c|}{$318.15 \mathrm{~K}$} \\
\hline & Expt. & Lit.[Ref] & Expt. & Lit. [Ref] & Expt. & Lit. [Ref] & Expt. & Lit. [Ref] \\
\hline $\begin{array}{c}\operatorname{Density}(\rho) \\
\mathrm{kg} / \mathrm{m}^{3}\end{array}$ & 1026.2 & $\begin{array}{c}1022.8[8] \\
1010.9[9] \\
1016.0[10]\end{array}$ & 1015.9 & $1010.9[10]$ & 1009.4 & $\begin{array}{c}1004.9[8] \\
1008.3[10]\end{array}$ & 1003.6 & $1007.4[10]$ \\
\hline $\begin{array}{c}\text { Viscosity }(\eta) \\
\mathrm{Ns} / \mathrm{m}^{2}\end{array}$ & 3.0248 & $\begin{array}{c}3.0270[7] \\
3.1767[10]\end{array}$ & 2.6349 & $\begin{array}{c}2.6350[7] \\
2.7238[10]\end{array}$ & 2.3447 & $\begin{array}{c}2.3036[7] \\
2.3552[10]\end{array}$ & 2.0564 & $\begin{array}{c}2.0474[7] \\
2.0826[10]\end{array}$ \\
\hline $\begin{array}{c}\text { Velocity(U) } \\
\mathrm{m} / \mathrm{s}\end{array}$ & 1623.4 & $\begin{array}{c}1614.5[7] \\
1615.2[8] \\
1614.0[9] \\
1629.0[10]\end{array}$ & 1598.4 & $\begin{array}{c}1595.1[7] \\
1611.0[10]\end{array}$ & 1583.9 & $\begin{array}{c}1574.4[7] \\
1582.6[8] \\
1602.0[10]\end{array}$ & 1551.4 & $\begin{array}{c}1554.9[7] \\
1578.0[10]\end{array}$ \\
\hline
\end{tabular}

Table 2. Ultrasonic velocity (U), Density $(\rho)$, Viscosity $(\eta)$, adiabatic compressibility $\left(\beta_{\mathrm{ad}}\right)$, inter molecular free length $\left(\mathrm{L}_{\mathrm{f}}\right)$, molar volume $\left(\mathrm{V}_{\mathrm{m}}\right)$, Acoustic Impedance $(\mathrm{Z})$

\begin{tabular}{|c|c|c|c|c|c|c|c|c|}
\hline$\underset{\substack{0 \\
\stackrel{0}{0}}}{\stackrel{0}{0}}$ & 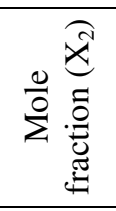 & 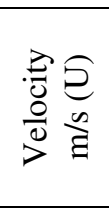 & 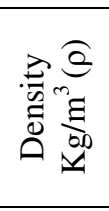 & 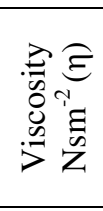 & 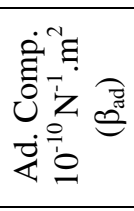 & 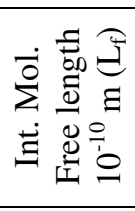 & 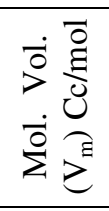 & 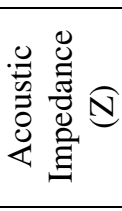 \\
\hline \multicolumn{9}{|c|}{$303.15 \mathrm{~K}$} \\
\hline 0.0000 & 1.0000 & 1623.4 & 1026.2 & 3.0248 & 3.6976 & 3.9900 & 90.752 & 1.6659 \\
\hline 0.0480 & 0.9519 & 1580.9 & 1003.6 & 3.4056 & 3.987 & 4.1433 & 103.2 & 1.5866 \\
\hline 0.1145 & 0.8879 & 1538.3 & 972.4 & 3.7864 & 4.3456 & 4.3256 & 120.82 & 1.4959 \\
\hline 0.2015 & 0.7984 & 1495.8 & 949.5 & 4.1672 & 4.7071 & 4.5019 & 144.22 & 1.4203 \\
\hline 0.3354 & 0.6645 & 1453.3 & 927.3 & 4.548 & 5.106 & 4.6888 & 179.07 & 1.3476 \\
\hline 0.5578 & 0.4421 & 1410.8 & 898.2 & 4.9288 & 5.5941 & 4.9077 & 238.71 & 1.2671 \\
\hline 1.0000 & 0.0000 & 1368.2 & 863.5 & 5.3096 & 6.1862 & 5.1610 & 359.61 & 1.1815 \\
\hline
\end{tabular}




\begin{tabular}{|c|c|c|c|c|c|c|c|c|}
\hline \multicolumn{9}{|c|}{$308.15 \mathrm{~K}$} \\
\hline 0.0000 & 1.0000 & 1598.4 & 1015.9 & 2.6349 & 3.8528 & 4.1122 & 91.672 & 1.6238 \\
\hline 0.0480 & 0.9519 & 1555.5 & 996.4 & 2.9818 & 4.148 & 4.2668 & 104 & 1.5499 \\
\hline 0.1145 & 0.8879 & 1512.5 & 966.5 & 3.3287 & 4.5226 & 4.4553 & 121.68 & 1.4619 \\
\hline 0.2015 & 0.7984 & 1469.6 & 945.1 & 3.6756 & 4.8991 & 4.6371 & 145.08 & 1.3889 \\
\hline 0.3354 & 0.6645 & 1426.7 & 922.6 & 4.0225 & 5.3252 & 4.8345 & 180.25 & 1.3163 \\
\hline 0.5578 & 0.4421 & 1383.8 & 894.2 & 4.3694 & 5.8405 & 5.0630 & 240.09 & 1.2373 \\
\hline 1.0000 & 0.0000 & 1340.8 & 859.3 & 4.7163 & 6.4731 & 5.3302 & 361.36 & 1.1522 \\
\hline \multicolumn{9}{|c|}{$313.15 \mathrm{~K}$} \\
\hline 0.0000 & 1.0000 & 1583.9 & 1009.4 & 2.3447 & 3.9489 & 4.2029 & 92.263 & 1.5988 \\
\hline 0.0480 & 0.9519 & 1540.6 & 993.7 & 2.6557 & 4.24 & 4.3550 & 104.31 & 1.5309 \\
\hline 0.1145 & 0.8879 & 1497.3 & 963.8 & 2.9667 & 4.628 & 4.5500 & 122.06 & 1.4431 \\
\hline 0.2015 & 0.7984 & 1454 & 943.2 & 3.2777 & 5.015 & 4.7364 & 145.45 & 1.3714 \\
\hline 0.3354 & 0.6645 & 1410.7 & 919.8 & 3.5887 & 5.4631 & 4.9434 & 180.91 & 1.2976 \\
\hline 0.5578 & 0.4421 & 1367.4 & 891.2 & 3.8997 & 6.0011 & 5.1812 & 241.02 & 1.2186 \\
\hline 1.0000 & 0.0000 & 1324.1 & 855.6 & 4.2107 & 6.6663 & 5.4608 & 362.93 & 1.1329 \\
\hline \multicolumn{9}{|c|}{ 318.15 K } \\
\hline 0.0000 & 1.0000 & 1551.4 & 1003.6 & 2.0564 & 4.1399 & 4.344 & 92.796 & 1.557 \\
\hline 0.0480 & 0.9519 & 1510.4 & 990.1 & 2.3454 & 4.4276 & 4.4924 & 104.7 & 1.4954 \\
\hline 0.1145 & 0.8879 & 1469.3 & 961.4 & 2.6344 & 4.8181 & 4.6864 & 122.41 & 1.4126 \\
\hline 0.2015 & 0.7984 & 1428.3 & 940.6 & 2.9234 & 5.2118 & 4.8741 & 145.92 & 1.3434 \\
\hline 0.3354 & 0.6645 & 1387.2 & 916.8 & 3.2124 & 5.6682 & 5.0830 & 181.59 & 1.2718 \\
\hline 0.5578 & 0.4421 & 1346.2 & 887.8 & 3.5014 & 6.2158 & 5.3229 & 242.05 & 1.1951 \\
\hline 1.0000 & 0.0000 & 1305.1 & 852.1 & 3.7904 & 6.89 & 5.6041 & 364.42 & 1.1121 \\
\hline
\end{tabular}

Table 3. Excess adiabatic compressibility $\left(\Delta \beta_{a d}\right)$, excess inter molecular free length $\left(L_{f}{ }^{E}\right)$, excess impedance $\left(\mathrm{Z}^{\mathrm{E}}\right)$, excess molar volume $\left(\mathrm{V}_{\mathrm{m}}^{\mathrm{E}}\right)$, excess viscosity $(\Delta \eta)$

\begin{tabular}{cccccc}
\hline$\left(\mathrm{X}_{1}\right)$ & $\Delta \beta_{\mathrm{ad}}$ & $\mathrm{L}_{\mathrm{f}}{ }^{\mathrm{E}}$ & $\mathrm{Z}^{\mathrm{E}}$ & $\mathrm{V}_{\mathrm{m}}{ }^{\mathrm{E}}$ & $\Delta \eta$ \\
\hline 0.0000 & 0.0000 & 0.0000 & 0.0000 & 0.0000 & 0.0000 \\
0.0480 & 0.1699 & 0.097 & -0.0560 & -0.4672 & 0.271 \\
0.1145 & 0.3692 & 0.2043 & -0.1161 & -0.0542 & 0.5056 \\
0.2015 & 0.508 & 0.2759 & -0.1484 & -0.7122 & 0.682 \\
0.3354 & 0.5737 & 0.306 & -0.1562 & -1.8672 & 0.7568 \\
0.5578 & 0.5081 & 0.2645 & -0.1291 & -2.0334 & 0.6294 \\
1.0000 & 0.0000 & 0.0000 & 0.0000 & 0.0000 & 0.0000 \\
\hline 0.0000 & 0.0000 & 0.0000 & 0.0000 & 0.0000 & 0.0000 \\
0.0480 & 0.1687 & 0.096 & -0.0512 & -0.6930 & 0.2464 \\
0.1145 & 0.3748 & 0.206 & -0.1092 & -0.3540 & 0.4595 \\
0.2015 & 0.5161 & 0.278 & -0.1396 & -1.1610 & 0.6195 \\
0.3354 & 0.5904 & 0.312 & -0.1495 & -2.1954 & 0.687 \\
0.5578 & 0.5225 & 0.27 & -0.1239 & -2.3861 & 0.5707 \\
1.0000 & 0.0000 & 0.0000 & 0.0000 & 0.0000 & 0.0000 \\
\hline 0.0000 & 0.0000 & & \\
\hline \multicolumn{7}{c}{0.0000} \\
\hline \multicolumn{7}{c}{0.0000} & 0.0000 & 0.0000 \\
\hline
\end{tabular}




\begin{tabular}{cccccc}
\hline 0.0480 & 0.1596 & 0.0913 & -0.0452 & -1.0531 & 0.2207 \\
0.1145 & 0.3726 & 0.2052 & -0.1035 & -0.724 & 0.4116 \\
0.2015 & 0.5152 & 0.2785 & -0.1334 & -1.6692 & 0.5548 \\
0.3354 & 0.5982 & 0.3165 & -0.1446 & -2.5836 & 0.615 \\
0.5578 & 0.5313 & 0.2742 & -0.1195 & -2.7269 & 0.5106 \\
1.0000 & 0.0000 & 0.0000 & 0.0000 & 0.0000 & 0.0000 \\
\hline \multicolumn{7}{c}{$\mathbf{3 1 8 . 1 5 ~ K}$} & & & \\
\hline 0.0000 & 0.0000 & 0.0000 & 0.0000 & 0.0000 & 0.0000 \\
0.0480 & 0.1544 & 0.0873 & -0.0400 & -1.2575 & 0.2049 \\
0.1145 & 0.3676 & 0.2120 & -0.0942 & -1.066 & 0.3821 \\
0.2015 & 0.5137 & 0.2743 & -0.1233 & -2.0051 & 0.5150 \\
0.3354 & 0.6003 & 0.3138 & -0.1351 & -2.8569 & 0.5708 \\
0.5578 & 0.5356 & 0.2731 & -0.1127 & -2.883 & 0.4738 \\
1.0000 & 0.0000 & 0.0000 & 0.0000 & 0.0000 & 0.0000 \\
\hline
\end{tabular}

Theory and calculations

In order to examine the inter molecular interactions in liquid mixtures of ethyl oleate with Aniline, experiments were conducted to find the density, viscosity and velocity of $2 \mathrm{MHz}$ ultrasonic waves for pure liquids and for binary liquid mixtures. The results of pure liquids are compared with literature values for assessment. From the experimental data of binary mixtures (Table 2), the derived, excess values were calculated at various mole fractions of ethyl oleate for understanding inter and intra molecular interactions at each temperature. The derived and excess values are calculated by using the fallowing relations

Adiabatic compressibility $\left(\beta_{a d}\right)$

$\mathrm{B}_{\mathrm{ad}}=\left(\rho \mathrm{U}_{2}\right)^{-1}$

Intermolecular free length $\left(L_{f}\right)$

$\mathrm{L}_{\mathrm{f}}=\mathrm{K} \sqrt{\beta_{\mathrm{ad}}}$

Molar volume of the binary liquid mixture $\left(V_{m}\right)$

The molar volume of the system at every mole fraction for the mixture is given by $\mathrm{V}_{\mathrm{m}}=\mathrm{M}_{\mathrm{eff}} / \rho_{\text {mix }}$ where $\mathrm{M}_{\mathrm{eff}}=\mathrm{M}_{1} \mathrm{X}_{1}+\mathrm{M}_{2} \mathrm{X}_{2} /\left(\mathrm{X}_{1}+\mathrm{X}_{2}\right)$

Free volume $\left(V_{f}\right)$

The free volumes of the binary mixtures have been computed using its relationship with the ultrasonic velocity and viscosity as given below

$$
\mathrm{V}_{\mathrm{f}}=\left(\frac{\mathrm{MU}}{\mathrm{K} \eta}\right)^{\frac{3}{2}}
$$

Where $\mathrm{k}$ is a constant, which is independent of temperature and its value is $4.28 \times 10^{9}$ for all liquids.

\section{Specific acoustic impedance (Z)}

The ultrasonic velocity is influenced by the acoustic impedance $(Z)$, which is given by the relation

$\mathrm{Z}=\rho \mathrm{U}$ 


\section{Excess thermodynamic parameters}

With the help of excess acoustic parameters the extent of deviation from the ideal behavior of binary mixture can be estimated (Table 3 ). The difference between the thermodynamic function of mixing for a real system and the value corresponding to a perfect solution at the same temperature, pressure and composition is called the thermodynamic excess function, denoted by $\mathrm{Y}^{\mathrm{E}}$.

Excess value $\mathrm{Y}^{\mathrm{E}}$ for each parameter can compute by using the general formula $\mathrm{Y}^{\mathrm{E}}=\mathrm{Y}-\left(\mathrm{Y}_{1} \mathrm{X}_{1}+\mathrm{Y}_{2} \mathrm{X}_{2}\right)$

Where $\mathrm{Y}$ is the parameter under consideration, $\mathrm{X}_{1}$ and $\mathrm{X}_{2}$ are mole fractions of two liquids ethyl oleate and other organic compound under consideration respectively of the binary system.

\section{Deviation in adiabatic compressibility $\left(\Delta \beta_{a d}\right)$}

The difference of the adiabatic compressibility of the mixture and the sum of the fractional contributory adiabatic compressibilities of the two liquids is the deviation in adiabatic compressibility. At a given mole fraction it is given by

$\Delta \beta_{\mathrm{ad}}=\beta_{\mathrm{ad}-}\left(\beta_{\mathrm{ad} 1} \mathrm{X}_{1+} \beta_{\mathrm{ad} 2} \mathrm{X}_{2}\right)$

\section{Excess free length $\left(L_{f}^{E}\right)$}

The excess free length can be calculated with formula

$\mathrm{L}_{\mathrm{f}}=\mathrm{L}_{\mathrm{f}}-\left(\mathrm{L}_{\mathrm{f} 1} \mathrm{X}_{1}+\mathrm{L}_{\mathrm{f} 2} \mathrm{X}_{2}\right)$

Excess acoustic impudence $\left(Z^{E}\right)$

Excess acoustic impedance can be calculated by the relation

$\mathrm{Z}^{\mathrm{E}}=\mathrm{Z}-\left(\mathrm{Z}_{1} \mathrm{X}_{1}+\mathrm{Z}_{2} \mathrm{X}_{2}\right)$

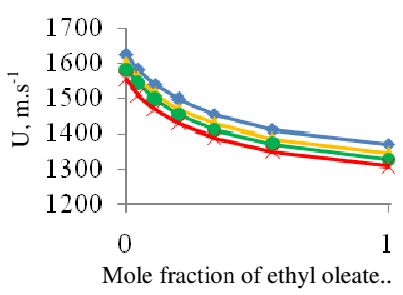

Figure 1. Ultrasonic

Velocity $v s$. mole fraction of ethyl oleate $\left(X_{1}\right)$

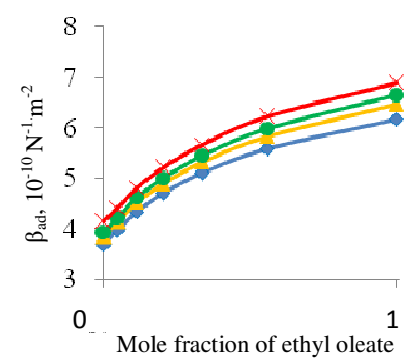

Figure 4. Adiabatic compressibility $v s$. mole fraction of ethyl oleate $\left(\mathrm{X}_{1}\right)$

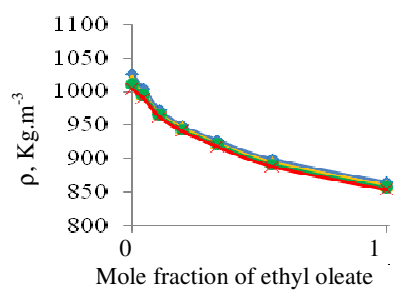

Figure 2. Density vs. mole fraction of ethyl oleate $\left(X_{1}\right)$

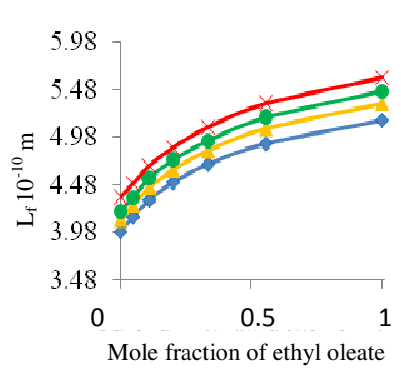

Figure 5. Intermolecular free Length $v s$. mole fraction of ethyl oleate $\left(\mathrm{X}_{1}\right)$

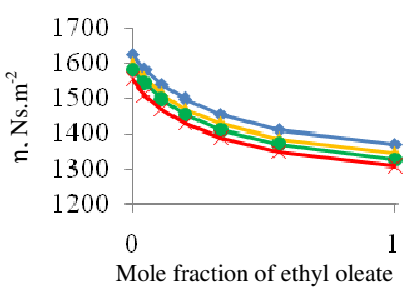

Figure 3:Viscocity vs. mole fraction of ethyl oleate $\left(X_{1}\right)$

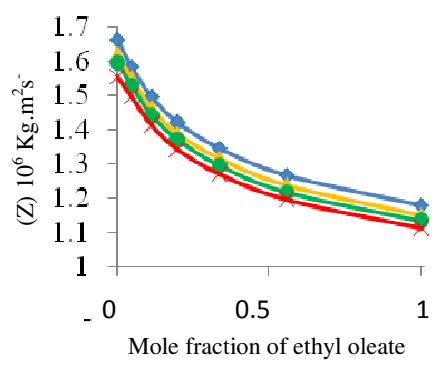

Figure 6. Acoustic impedance $v s$. mole fraction of ethyl oleate $\left(\mathrm{X}_{1}\right)$ 


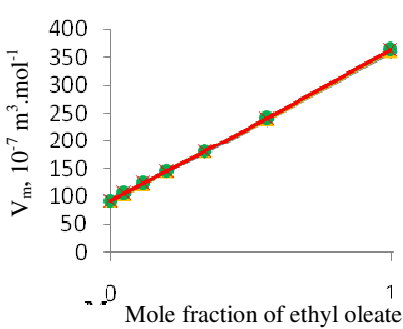

Figure 7. Molar volume vs. mole fraction of ethyl oleate $\left(\mathrm{X}_{1}\right)$

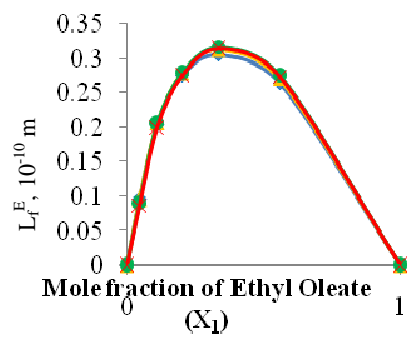

Figure 10. Excess intermolecular free length $v s$. mole fraction of ethyl oleate $\left(\mathrm{X}_{1}\right)$

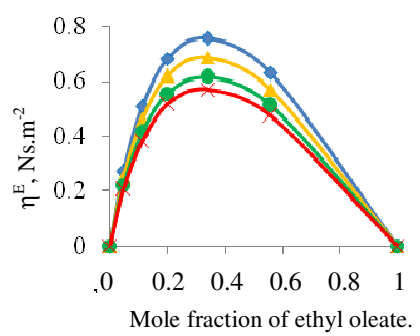

Figure 8. Deviation in viscosity $v s$. mole fraction of ethyl oleate $\left(X_{1}\right)$

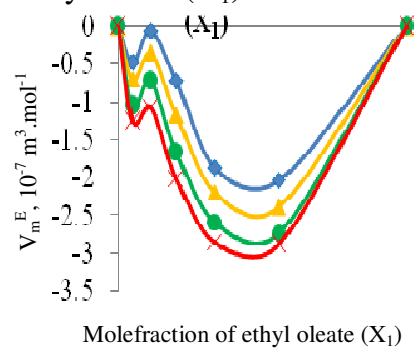

Figure 11. Excess molar volume $v s$. mole fraction of ethyl oleate $\left(\mathrm{X}_{1}\right)$

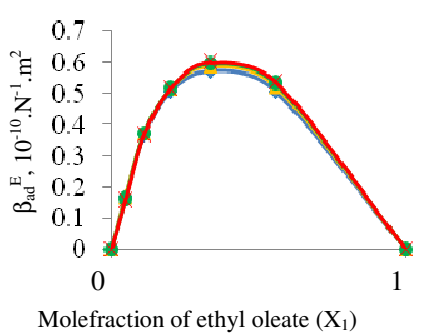

Figure 9. Excess adia. compressibility $v s$. molefraction of ethyl oleate $\left(\mathrm{X}_{1}\right)$

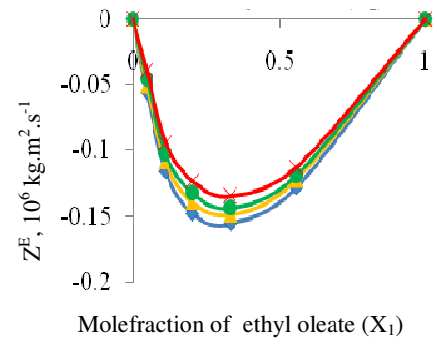

Figure 12. Excess acoustic impedance $v s$. mole fraction of ethyl oleate $\left(\mathrm{X}_{1}\right)$

\section{Results and Discussion}

\section{FT IR studies}

There is a characteristic absorption at $1737 \mathrm{~cm}^{-1}$, which is attributed to the stretching frequency of the $\mathrm{C}=\mathrm{O}$ bond of the ester. The absorption bands at 3431 and $3360 \mathrm{~cm}^{-1}$ which is attributed to the stretching frequencies of free N-H bond in amine. The band at $3071 \mathrm{~cm}^{-1}$ referred to the stretching frequency of aromatic $=\mathrm{C}-\mathrm{H}$ bond. The frequency range at 1127 and $1107 \mathrm{~cm}^{-1}$ belongs to C-O stretching.

The absorption bands at 3462 and $3368 \mathrm{~cm}^{-1}$ which is attributed to the stretching frequencies of free N-H bond in amine. The peak at $1724 \mathrm{~cm}^{-1}$, which is attributed to the stretching frequency of the $\mathrm{C}=\mathrm{O}$ bond of the ester. The band at $3071 \mathrm{~cm}^{-1}$ referred to the stretching frequency of aromatic $=\mathrm{C}-\mathrm{H}$ bond ${ }^{11}$.

The hydrogen bond formation between the proton donor N-H of aniline and carbonyl group $(\mathrm{C}=\mathrm{O})$ of ethyl oleate using FTIR spectroscopy.

From the above tables and graphs (Figure 1-12) it can be seen that for the ethyl oleate + aniline the experimental parameters ultrasonic velocity, density and viscosity are changing with mole fraction of ethyl oleate at all the temperatures. The derived parameters adiabatic compressibility, intermolecular free length, molar volume, free volume and are increasing and impedance, internal energy, ultrasonic velocity and density are decreasing and viscosity is increasing with increase in mole fraction of ethyl oleate. Except acoustic impedance and internal pressure all the derived parameters are increasing with the increase in mole fraction of ethyl oleate at all the temperatures individually under consideration. Figure 13 and 14 represent the FTIR spectra for pure compounds of ethyl oleate and aniline and mixture of both respectively. Figure 15 represents the hydrogen bonding formed in the mixture. 

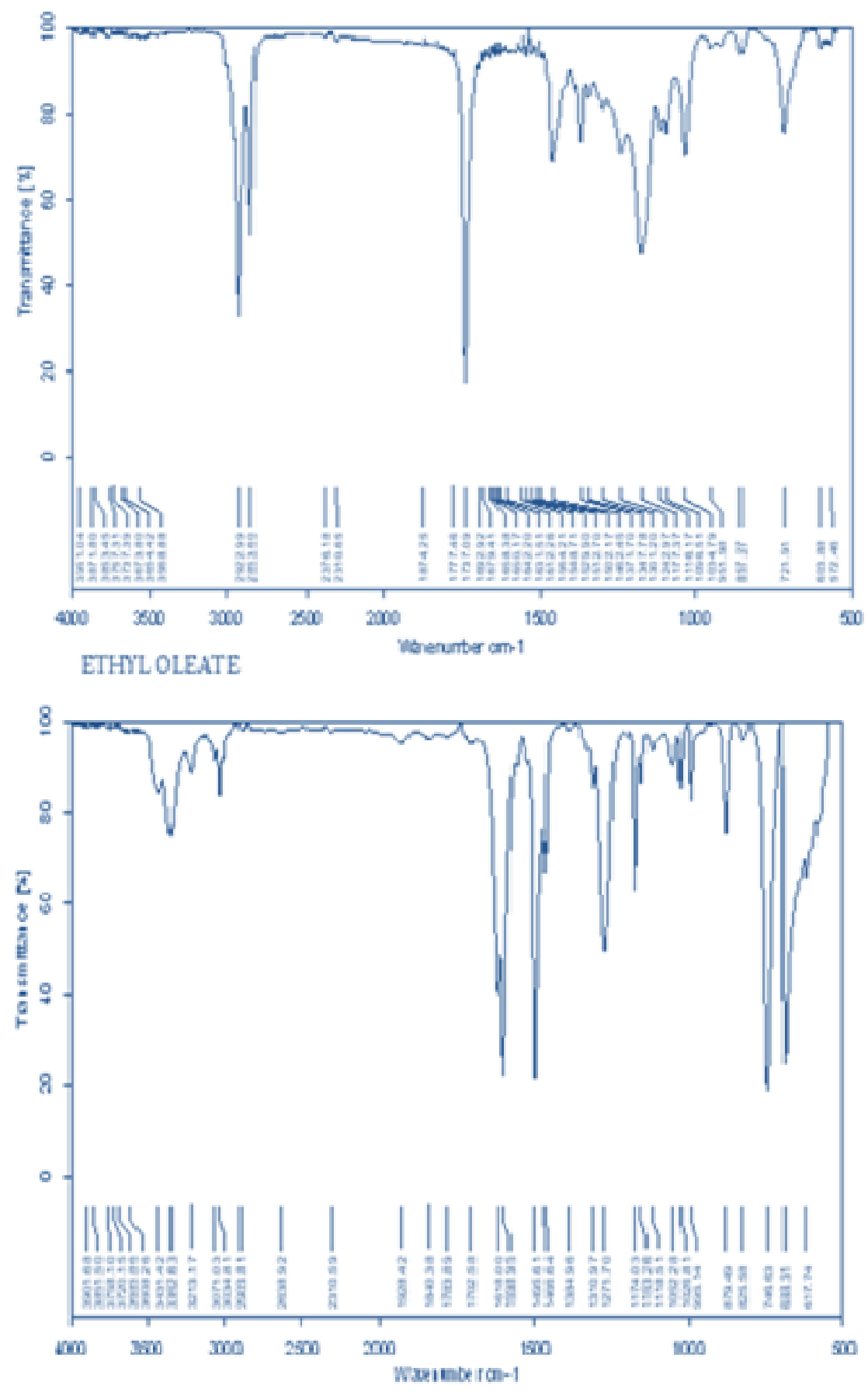

ANIIDE

Figure 13. FTIR spectrum of pure ethyl oleate and pure aniline 


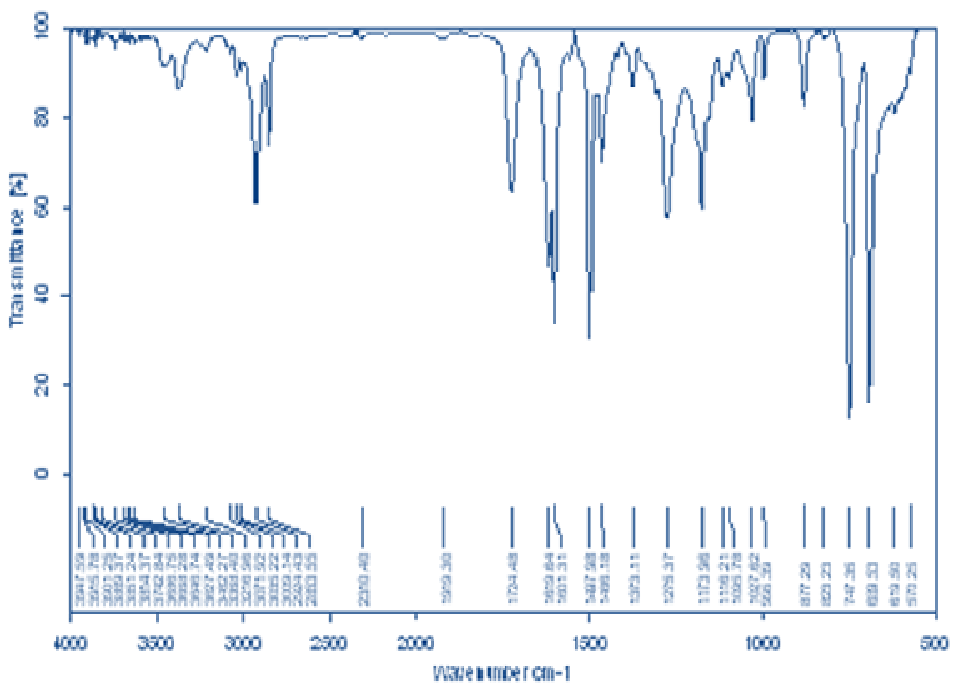

ETHYLOLEATE + ANILNE

Figure 14. FTIR spectrum of ethyl oleate + aniline

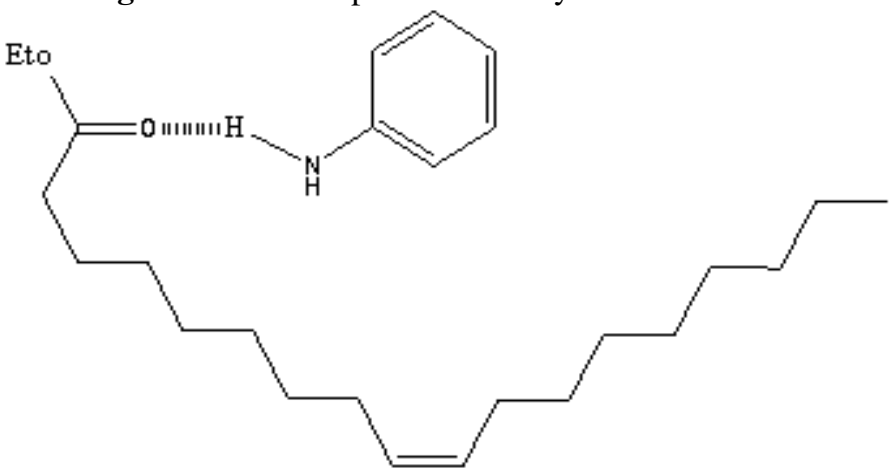

Figure 15. Hydrogen bonding of ethyl oleate + aniline

The excess velocity $\left(\mathrm{U}^{\mathrm{E}}\right)$, excess impedance $\left(\mathrm{Z}^{\mathrm{E}}\right)$, excess molar volume $\left(\mathrm{V}_{\mathrm{m}}^{\mathrm{E}}\right)$, excess free volume $\left(\mathrm{V}_{f}^{\mathrm{E}}\right)$ and excess internal pressure $\left(\Pi^{\mathrm{E}}\right)$ are showing negative values and remaining all are showing positive values in the study temperature range which were represented as graphs.

The negative excess molar volume $\left(\mathrm{V}_{\mathrm{m}}{ }^{\mathrm{E}}\right)^{12}$ and positive excess viscosity $(\Delta \eta)$ represent the strong interaction between the unlike molecules of the binary mixture, like dipole-dipole hydrogen bonding. Though the excess adiabatic compressibility $\left(\Delta \beta_{\mathrm{ad}}\right)$ values here are positive the magnitudes are low. In aniline self-associated through hydrogen bonding of their amino group $(\mathrm{N}-\mathrm{H})$ and ester molecules are polar group $\mathrm{C}=\mathrm{O}$, thus the mixing of amine molecule with ester molecule forming new $\mathrm{H}$-bond $(\mathrm{N}-\mathrm{H}$ of aniline and oxygen atom of ester.

\section{Conclusion}

The ultrasonic velocity, density, viscosity and other related experimental, derived and their excess parameters were calculated. The miscible organic binary liquid mixture of ethyl oleate 
and aniline shows the negative excess molar volume $\left(\mathrm{V}_{\mathrm{m}}^{\mathrm{E}}\right)$ and positive excess viscosity $(\Delta \eta)$ represent the strong interaction between the unlike molecules of the binary mixture, like hydrogen bonding.

\section{Acknowledgments}

The authors are very much grateful to Andhra University for providing infrastructure facilities, the research guide Prof. B.Venkateswera Rao and also thankful to UGC for sanctioning fellowship which financially helped for procuring instruments and chemicals.

\section{References}

1. $\quad$ Lagemann R T and Dunbar W S, J Phys Chem., 1945, 49, 428.

2. $\quad$ Chauhan S K and Singh V R, Indian J Pure Appl Phys., 1993, 31(9), 635-638.

3. Blokhra R L and Nag A, Indian J Pure Appl Phys., 1991, 29, 756-759.

4. Joseph Kestin, MordechaiSokolov, Willium A Wakeham, J Phys Chem Ref Data, 1978, 7(3), 941; DOI:10.1063/1.555581

5. Instruction manuals for ultrasonic interferometer model F-05, constant temperature water bath Mittal Enterprises.

6. American Society for Testing and Materials (ASTM) Standard D6751. ASTM: West Conshohocken, PA, 2009.

7. Anil Kumar Nain, Fluid Phase Equilibria, 2007, 259(2), 218-227; DOI:10.1016/j.fluid.2007.07.016

8. Oswal S L, Pandiyanb V, Krishnakumar B and Vasantharani P, Thermochimica Acta, 2010, 507-508, 27-34; DOI:10.1016/j.tca.2010.04.025

9. Palaniappan Lakshmanan and Mahendran Govindasamy, Turk J Phys., 2011, 35, 303.

10. Sreedevi Y, Srinivasu Ch, Fakruddin S K and Narendra K, J Chem, Biological Phys Sci., 2013, 3(1), 454-463.

11. Wojciechowski P M, Zierkiewicz W, Michalska D and Hobza P, J Chem Phys., 2003, 118, 10900-10911; DOI:10.1063/1.1574788

12. Ayasen Jermaine Kemeakegha, Grace Agbizu Cookey and Welford-Abbey Lolo Izonfuo, J Termodynamics, 2015, ID 782138; DOI:10.1155/2015/782138 